\title{
EFEITO DA APLICAÇÃO DE NITRATO NA REDUÇÃO BIOGÊNICA DE SULFETO SOB DIFERENTES CONCENTRAÇÕES INICIAIS DE BACTÉRIAS REDUTORAS DE NITRATO E SULFATO
}

\author{
Kally Alves de Sousa, Magali Christe Cammarota* e Eliana Flávia Camporese Sérvulo \\ Departamento de Engenharia Bioquímica, Escola de Química, Universidade Federal do Rio de Janeiro, Av. Horácio Macedo 2030 , \\ Centro de Tecnologia, Bl. E, Ilha do Fundão, 21941-909 Rio de Janeiro - RJ, Brasil
}

Recebido em 4/1/09; aceito em 5/8/09; publicado na web em 11/1/10

\begin{abstract}
EFFECT OF NITRATE APPLICATION ON REDUCTION OF BIOGENIC SULPHIDE UNDER DIFFERENT INITIAL CONCENTRATIONS OF NITRATE AND SULPHATE-REDUCING BACTERIA. The effect of sodium nitrate application in the reduction of biogenic sulphide was evaluated through a $2^{\mathrm{k}}$ complete factorial design, using as variable response the production of sulfide at intervals of incubation of 7, 14 and 28 days. The most effective condition for reducing the sulphide production (final concentrations from 0.4 to 1.6 $\mathrm{mg} \mathrm{S}^{2-} \mathrm{L}^{-1}$ ) was obtained with an initial population of sulphate-reducing bacteria and nitrate-reducing bacteria of $10^{4} \mathrm{MPN} \mathrm{mL}^{-1}$ and 427.5 $\mathrm{mg} \mathrm{L}^{-1}$ nitrate. The results also suggested that the applications of nitrate to control the process of souring should follow a continuous scheme.
\end{abstract}

Keywords: nitrate; sulphate-reducing bacteria; nitrate-reducing bacteria.

\section{INTRODUÇÃO}

A acidificação dos reservatórios (souring) é um dos problemas cruciais da exploração de petróleo. Este problema tem origem na injeção de água do mar em poços adjacentes aos produtores, prática comum em campos offshore devido à disponibilidade deste recurso hídrico. ${ }^{1-3}$ Entretanto, a água do mar contém elevado teor de sulfatos (em torno de $3000 \mathrm{mg} \mathrm{L}^{-1}$ ), que sofrem redução a sulfeto por ação de bactérias redutoras de sulfato (BRS) em ambientes anaeróbios.

O sulfeto total produzido pela atividade microbiana compreende as formas $\mathrm{H}_{2} \mathrm{~S}_{\text {, }} \mathrm{HS}^{-}$e $\mathrm{S}^{2-}$, cuja distribuição está relacionada ao $\mathrm{pH}$ do meio. Para valores de $\mathrm{pH}$ menores que $7, \mathrm{H}_{2} \mathrm{~S}$ é o principal componente na fase aquosa; a forma dissociada HS é predominante para valores de $\mathrm{pH}$ entre 7 e 14. Quando o $\mathrm{pH}$ é exatamente 7, tem-se $50 \%$ do sulfeto na forma de $\mathrm{H}_{2} \mathrm{~S}$ e $50 \%$ na forma de $\mathrm{HS}^{-} .{ }^{4}$ Sob condições anaeróbias, o sulfeto é altamente reativo, corrosivo e tóxico, sendo o sulfeto de hidrogênio não dissociado $\left(\mathrm{H}_{2} \mathrm{~S}\right)$ considerado a forma mais tóxica do sulfeto. $\mathrm{O} \mathrm{H}_{2} \mathrm{~S}$, por ser uma molécula neutra, pode facilmente se difundir através da membrana celular para o citoplasma, onde pode reagir com componentes celulares. ${ }^{5,6}$

A intensificação do souring também pode ser atribuída à reinjeção da água produzida durante o processo de produção de petróleo, uma vez que esta contém nutrientes utilizados por bactérias redutoras de sulfato, além de reintroduzir micro-organismos já adaptados às condições do reservatório. A reutilização da água produzida constitui uma alternativa de manejo, pois sua disposição acarreta sérios danos ambientais, sendo este procedimento adotado em locais em que a legislação ambiental é mais restritiva, como nos campos do Mar do Norte. ${ }^{7-11}$

A acidificação de reservatórios, associada à recuperação secundária do petróleo, pode resultar em corrosão, obstrução dos poços injetores e produtores pela deposição de $\mathrm{FeS}$, redução da produtividade dos poços e da qualidade do petróleo produzido. ${ }^{2,4,10}$ Todos estes problemas justificam a importância de se desenvolver estudos para o controle ou a prevenção do souring em reservatórios de petróleo.

A aplicação de biocidas tem sido a forma de controle mais adotada para o controle da produção de sulfeto por ação de BRS. ${ }^{12}$ No entanto, esta alternativa nem sempre é adequada, pois na maioria das vezes

*e-mail: christe@eq.ufrj.br envolve custos elevados e a eficiência alcançada é baixa. A inibição das BRS pode ser conseguida pelo uso de molibdato e outros produtos que, na maioria dos casos, não são aplicáveis em maior escala devido ao alto investimento. ${ }^{13}$ Existem opções como a nanofiltração para dessulfatação do fluido injetor e a esterilização com radiação ultravioleta, que também apresentam altos custos de implantação e inviabilidade de aplicação em grande escala. ${ }^{14}$

Uma estratégia de controle que vem sendo cada vez mais explorada no controle da atividade de BRS e, consequentemente, na redução da produção de $\mathrm{H}_{2} \mathrm{~S}$, tem sido a aplicação de nitrato. Essa aplicação, em substituição aos métodos normalmente empregados, implica em redução dos custos de aplicação e agressões ao ambiente. A aplicação de nitrato para controle de BRS tem se tornado prática comum em grandes empresas petrolíferas, principalmente nas atividades de recuperação de petróleo em reservatórios maduros. A aplicação de nitrato assegura a atividade de bactérias redutoras de nitrato (BRN), uma vez que a redução do nitrato permite aos micro-organismos um ganho energético consideravelmente maior do que a redução de sulfato. Sendo assim, a presença de nitrato no sistema estimula o crescimento de $\mathrm{BRN}$, que em maior concentração podem competir mais intensamente por fontes de carbono e nutrientes, dificultando o crescimento das BRS. Esta técnica também favorece a atividade de espécies de bactérias redutoras de nitrato capazes de oxidar sulfetos (BRN-OS), resultando na remoção do sulfeto já formado do ambiente e em aumento do potencial redox, inibindo ainda mais o crescimento das BRS. Cabe destacar a existência de espécies de BRS capazes de também utilizar o nitrato como receptor final de elétrons, tendo como consequência a não formação do sulfeto biogênico. ${ }^{14-18}$

A ação do nitrato tem se mostrado efetiva na inibição seletiva de BRS e seu uso mais conveniente do que os tratamentos convencionais. Entretanto, o uso do nitrato está condicionado ao custo e, principalmente, ao seu modo de aplicação, além da fase em que os micro-organismos se encontram no sistema, se planctônica ou séssil. As células microbianas sésseis encontram-se imersas em uma matriz exopolimérica que pode dificultar a difusão do nitrato. ${ }^{19}$ Deve-se ainda considerar que o nitrato e seus intermediários, em especial o nitrito, são agentes que podem propiciar a corrosão de metais existentes nos sistemas. Ressalta-se que o efeito do tratamento com nitrato ainda não foi devidamente estabelecido. Ademais, a atividade microbiana 
específica e as características do sistema a ser tratado devem ser estudadas caso a caso.

Assim sendo, o objetivo principal desse estudo foi avaliar, através de planejamento fatorial $2^{\mathrm{k}}$, o efeito da aplicação de nitrato de sódio na redução biogênica de sulfeto mediante diferentes concentrações iniciais de BRN e BRS.

\section{PARTE EXPERIMENTAL}

\section{Micro-organismos e meios de cultivo}

Foram empregados um consórcio microbiano enriquecido de BRS isolado de campo de petróleo offshore da Petróleo Brasileiro S.A. (Petrobras) e uma cultura pura de BRN (Halomonas halodenitrificans - DSM ${ }^{\mathrm{T}}$ 735), adquirida da Coleção de Culturas DSMZ (Deutsche Sammlung von Mikroorganismen und Zellkulturen, Braunschweig, Alemanha). As culturas foram mantidas através de repiques mensais em meios específicos. Para o consórcio de BRS utilizou-se o meio Postgate E modificado ${ }^{20}$ e para a cultura de BRN empregou-se caldo nutriente acrescido de $0,5 \mathrm{~g} \mathrm{~L}^{-1} \mathrm{KNO}_{3}$, conforme indicado pela DSMZ. Após incubação a $30 \pm 1{ }^{\circ} \mathrm{C}$ por $72 \mathrm{~h}$, as culturas de BRS e BRN foram estocadas à temperatura ambiente e a $5{ }^{\circ} \mathrm{C}$, respectivamente.

Para os ensaios do planejamento experimental foi utilizado um meio constituído de água produzida (MAP) suplementada com sais essenciais (em g L${ }^{-1}: 0,5 \mathrm{KH}_{2} \mathrm{PO}_{4} ; 1,0 \mathrm{NH}_{4} \mathrm{Cl}$ ), extrato de levedura $\left(0,2 \mathrm{~g} \mathrm{~L}^{-1}\right)$ e ácidos orgânicos de cadeia curta como fonte de carbono na seguinte proporção: ácido lático $\left(60,8 \mathrm{~g} \mathrm{~L}^{-1}\right)$, ácido propiônico (50,0 $\left.\mathrm{g} \mathrm{L}^{-1}\right)$ e ácido butírico (44,6 $\left.\mathrm{g} \mathrm{L}^{-1}\right)$. A concentração dos ácidos orgânicos foi calculada de modo a se estabelecer a relação carbono/ sulfato do meio Postgate $\mathrm{E}^{20}$, cuja composição é específica para o cultivo de BRS. A composição deste meio foi definida com base no conteúdo de sulfato na água produzida (1650 $\left.\mathrm{mg} \mathrm{SO}_{4}{ }^{2-} \mathrm{L}^{-1}\right)$ e em estudos prévios em que o meio empregado também foi formulado com água produzida. ${ }^{21} \mathrm{O}$ meio foi ainda acrescido de $0,053 \mathrm{~g} \mathrm{~L}^{-1}$ de ácido ascórbico como agente redutor, a fim de se estabelecer condição de anaerobiose.

Todos os componentes foram solubilizados em água produzida e o pH do meio ajustado em 7,0 \pm 0,5 com adição de $\mathrm{NaOH} 1,0 \mathrm{~mol}$ $\mathrm{L}^{-1}$. A água produzida foi procedente de plataforma offshore (P-35) localizada na Bacia de Campos (Campos, Rio de Janeiro, Brasil) e os reagentes empregados no preparo dos meios de cultivo e na suplementação da água produzida foram de grau analítico (marca Vetec).
A condição de anaerobiose foi estabelecida por purga contínua de nitrogênio ( $28 \mathrm{~L} \mathrm{~min}^{-1}$ por $20 \mathrm{~min}$ ) efetuada durante o preparo do meio e a sua distribuição em frascos do tipo penicilina. Para manter inalteradas as propriedades físico-químicas da água produzida, os meios não foram esterilizados, sendo conduzido um controle abiótico para cada condição de ensaio do planejamento experimental descrito a seguir.

\section{Planejamento experimental}

Testes preliminares estabeleceram as condições para desenvolvimento do planejamento experimental e demonstraram que a água produzida, mesmo sem diluição, apresentava baixo teor de componentes inibitórios. Assim, foram avaliados os efeitos de três variáveis independentes sobre a produção biogênica de sulfeto de hidrogênio: $x_{1}$ - concentração inicial de BRS (NMP $\left.\mathrm{mL}^{-1}\right) ; \mathrm{x}_{2}$ - concentração inicial de BRN (NMP $\mathrm{mL}^{-1}$ ) e $\mathrm{x}_{3}$ - concentração inicial de nitrato $\left(\mathrm{mg} \mathrm{L}^{-1}\right)$. Para tanto, optou-se por um planejamento fatorial $2^{3}$ completo, tendo como variável resposta a produção de sulfeto a intervalos de incubação de 7, 14 e 28 dias. Para a estimativa do erro experimental e da existência de curvatura no modelo realizaram-se três ensaios no ponto central. Os coeficientes de regressão do modelo foram determinados pelo método dos mínimos quadrados e, como medida da adequação do modelo, utilizaram-se o coeficiente de correlação $\left(\mathrm{R}^{2}\right)$ e a análise residual. Os dados experimentais foram analisados usando-se o software Statistica versão 7.0. As figuras e tabelas apresentadas nos resultados também foram geradas usando-se este mesmo software. A Tabela 1 relaciona as variáveis envolvidas (valores reais e codificados) no processo e seus respectivos níveis.

Os experimentos foram conduzidos em frascos do tipo penicilina de $50 \mathrm{~mL}$ de capacidade com $30 \mathrm{~mL}$ de meio reacional (MAP). Os frascos foram inoculados com $5 \mathrm{~mL}$ do consórcio de BRS e $5 \mathrm{~mL}$ da cultura de BRN. As concentrações celulares dos inóculos de cada experimento foram estabelecidas por diluições seriadas, totalizando um volume final nos experimentos (inóculo e meio reacional) de 40 $\mathrm{mL}$. Utilizaram-se inóculos de BRS e BRN com 96 h de crescimento após prévia ativação nos meios Postgate E modificado e caldo nitrato para BRS e BRN, respectivamente. Diluições seriadas em solução salina redutora $(\mathrm{pH} 7,6)$ permitiram a obtenção de populações microbianas iniciais de $10^{1}, 10^{4}$ e $10^{7} \mathrm{NMP} \mathrm{mL}^{-1}$ de BRS e BRN. Os frascos foram incubados a $30^{\circ} \mathrm{C}$, sendo a produção de sulfeto medida no $7^{\circ}, 14^{\circ}$ e $28^{\circ}$ dia de incubação.

Tabela 1. Matriz do planejamento com valores reais e codificados das variáveis independentes e produção de sulfeto em diferentes tempos de incubação

\begin{tabular}{|c|c|c|c|c|c|c|c|c|c|}
\hline \multirow{3}{*}{ Exp. } & \multicolumn{3}{|c|}{ Variáveis codificadas } & \multicolumn{3}{|c|}{ Variáveis reais } & \multirow{2}{*}{\multicolumn{3}{|c|}{$\begin{array}{l}\text { Produção de } \mathrm{S}^{2-}\left(\mathrm{mg} \mathrm{L}^{-1}\right) \\
\text { Tempo de incubação (dias) }\end{array}$}} \\
\hline & \multirow[t]{2}{*}{ BRS } & \multirow{2}{*}{ BRN } & \multirow{2}{*}{$\mathrm{NO}_{3}^{-}$} & \multirow{2}{*}{$\begin{array}{c}\text { BRS } \\
\left(\mathrm{NMP} \mathrm{mL}^{-1}\right)\end{array}$} & \multirow{2}{*}{ 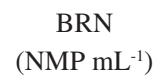 } & \multirow{2}{*}{$\begin{array}{c}\mathrm{NO}_{3}^{-} \\
\left(\mathrm{mg} \mathrm{L}^{-1}\right)\end{array}$} & & & \\
\hline & & & & & & & $7(\mathrm{Y} 1)$ & $14(\mathrm{Y} 2)$ & $28(\mathrm{Y} 3)$ \\
\hline 1 & -1 & -1 & -1 & $10^{1}$ & $10^{1}$ & 127,5 & 2,6 & 42,2 & 45,6 \\
\hline 2 & +1 & -1 & -1 & $10^{7}$ & $10^{1}$ & 127,5 & 26,4 & 27,3 & 41,9 \\
\hline 3 & -1 & +1 & -1 & $10^{1}$ & $10^{7}$ & 127,5 & 18,6 & 31,1 & 34,8 \\
\hline 4 & +1 & +1 & -1 & $10^{7}$ & $10^{7}$ & 127,5 & 39,2 & 40,0 & 43,3 \\
\hline 5 & -1 & -1 & +1 & $10^{1}$ & $10^{1}$ & 727,5 & 3,5 & 8,3 & 9,4 \\
\hline 6 & +1 & -1 & +1 & $10^{7}$ & $10^{1}$ & 727,5 & 12,7 & 23,9 & 52,9 \\
\hline 7 & -1 & +1 & +1 & $10^{1}$ & $10^{7}$ & 727,5 & 4,8 & 38,9 & 50,8 \\
\hline 8 & +1 & +1 & +1 & $10^{7}$ & $10^{7}$ & 727,5 & 34,5 & 34,4 & 41,4 \\
\hline 9 & 0 & 0 & 0 & $10^{4}$ & $10^{4}$ & 427,5 & 0,4 & 35,5 & 37,7 \\
\hline 10 & 0 & 0 & 0 & $10^{4}$ & $10^{4}$ & 427,5 & 0,7 & 32,5 & 41,5 \\
\hline 11 & 0 & 0 & 0 & $10^{4}$ & $10^{4}$ & 427,5 & 1,6 & 30,0 & 44,8 \\
\hline
\end{tabular}




\section{Procedimentos analíticos}

A determinação de sulfeto total na fase líquida seguiu uma adaptação do método colorimétrico usando N,N-dimetil- $p$-fenileno-diamina e cloreto férrico, conforme descrito por Jacobs et al...22 A adaptação do método consistiu do tratamento prévio de $1 \mathrm{~mL}$ da amostra com igual volume de ácido clorídrico concentrado em frasco do tipo penicilina de $10 \mathrm{~mL}$ de capacidade, a $70{ }^{\circ} \mathrm{C}$ por $10 \mathrm{~min}$, a fim de promover a dissolução dos sulfetos metálicos presentes na amostra. ${ }^{23}$ A leitura da absorbância foi feita no comprimento de $670 \mathrm{~nm}$ em espectrofotômetro UV-visível CAMSPEC, modelo 302, UK. A curva padrão usada como referência foi obtida com $\mathrm{Na}_{2} \mathrm{~S}$ mono-hidratado p.a. (Merck). ${ }^{22,23}$ A concentração de nitrato foi determinada por método espectrofotométrico (Ultraviolet Spectrophotometric Screening Method), segundo procedimento descrito no Standard Methods. ${ }^{24}$

\section{RESULTADOS E DISCUSSÃO}

Os meios de cultivo com água produzida permitiram o crescimento tanto de BRS como de BRN, assegurando sua viabilidade no decorrer dos ensaios. A Tabela 1 apresenta os valores da produção biogênica de sulfeto aos 7, 14 e 28 dias de incubação. Consideraramse, nos dados apresentados, os valores médios de produção de sulfeto já subtraídos dos valores obtidos nos respectivos controles abióticos, cujos valores foram inferiores a $1 \mathrm{mg} \mathrm{mL}^{-1}$.

Com os resultados obtidos foi possível determinar os coeficientes da regressão para os distintos tempos de incubação, como apresentado na Tabela 2. Os coeficientes de regressão das variáveis e suas interações foram estimados pelo método dos mínimos quadrados, tendo sido estabelecido um intervalo de confiança de $95 \%$.

Observa-se que para as respostas Y1, Y2 e Y3 a curvatura não foi significativa, ou seja, na região investigada não existiam termos quadráticos e os modelos comportaram-se de maneira linear. Deste modo, determinaram-se, para cada resposta, os modelos empíricos (1) a (3) já descartados de todos os parâmetros não significativos (com valor de p superior a 0,05 ).

$\mathrm{Y} 1=17,77+10,42 \cdot \mathrm{BRS}+6,50 \cdot \mathrm{BRN}-3,90 \cdot \mathrm{NO}_{3}{ }^{-}+2,17 \cdot \mathrm{BRS}+2,94$ BRS.BRN.NO

$\mathrm{Y} 2=30,75+5,33 \cdot \mathrm{BRN}-4,40 \cdot \mathrm{NO}_{3}^{-}+4,93 \cdot \mathrm{BRN} \cdot \mathrm{NO}_{3}{ }^{-}-5,51 \cdot \mathrm{BRS}$ BRN.NO

$\mathrm{Y} 3=40,01-8,13 \cdot \mathrm{BRS} \cdot \mathrm{BRN} \cdot \mathrm{NO}_{3}$

A validade dos modelos também foi verificada pela análise da variância através do teste $\mathrm{F}$, comparando-se os valores de $\mathrm{F}$ dos modelos com os valores de F críticos, como mostra a Tabela 3.

Enfatiza-se que, nas análises de variância dos modelos, levaram-se em conta apenas os parâmetros significativos, nos quais o valor de $\mathrm{p}$ se encontrava abaixo de 0,05 . Para as respostas Y1 e Y2, correspondentes aos tempos de incubação de 7 e 14 dias, respectivamente, observa-se que o modelo matemático foi altamente significativo, conseguindo explicar 99,6 e 93,6\% da variação total em torno da média, sendo os valores de F calculado $(184,78$ e 11,72) maiores que os valores de F crítico $(6,26)$. Nota-se que para essas respostas o teste de falta de ajuste não foi significativo, sendo os valores de $\mathrm{F}$ calculado $(10,28$ e 2,72 ) menores que o $\mathrm{F}$ crítico $(19,0)$, reafirmando que os dados se ajustaram bem ao modelo linear. No entanto, para a resposta Y3, correspondente a 28 dias de incubação, o valor do coeficiente de correlação foi consideravelmente baixo $\left(R^{2}=0,4052\right)$, com valor de $F$ calculado $(0,54)$ menor que o crítico $(6,26)$. Para este modelo, o teste de falta de ajuste passou a ser significativo, com valor de F calculado
Tabela 2. Coeficientes de regressão para as respostas Y1, Y2 e Y3

\begin{tabular}{|c|c|c|c|}
\hline Fatores & $\begin{array}{c}\text { Coef. } \\
\text { regressão }\end{array}$ & $\begin{array}{c}\text { Teste } \\
t \text {-Student }\end{array}$ & Valor de $\mathrm{p}$ \\
\hline \multicolumn{4}{|l|}{ Incubação: 7 dias (Y1) } \\
\hline Constante & 17,77 & 79,97 & 0,000156 \\
\hline Curvatura & $-2,16$ & $-3,78$ & 0,063547 \\
\hline Concentração inicial de BRS & 10,42 & 46,91 & 0,000454 \\
\hline Concentração inicial de BRN & 6,50 & 29,25 & 0,001167 \\
\hline Concentração inicial de nitrato & $-3,90$ & $-17,57$ & 0,003223 \\
\hline BRS x BRN & 2,17 & 9,77 & 0,010324 \\
\hline $\mathrm{BRS} \times \mathrm{NO}_{3}^{-}$ & $-0,70$ & $-3,15$ & 0,087717 \\
\hline $\mathrm{BRN} \times \mathrm{NO}_{3}^{-}$ & $-0,72$ & $-3,26$ & 0,082487 \\
\hline $\begin{array}{l}\text { BRS x BRN x } \mathrm{NO}_{3}^{-} \\
\text {Incubação: } 14 \text { dias (Y2) }\end{array}$ & 2,94 & 13,25 & 0,005645 \\
\hline Constante & 30,75 & 31,59 & 0,001001 \\
\hline Curvatura & 7,40 & 2,95 & 0,098273 \\
\hline Concentração inicial de BRS & 0,64 & 0,66 & 0,576466 \\
\hline Concentração inicial de BRN & 5,33 & 5,47 & 0,031799 \\
\hline Concentração inicial de nitrato & $-4,40$ & $-4,52$ & 0,045613 \\
\hline BRS x BRN & 0,47 & 0,48 & 0,677724 \\
\hline $\mathrm{BRS} \times \mathrm{NO}_{3}^{-}$ & 2,13 & 2,19 & 0,160334 \\
\hline $\mathrm{BRN} \times \mathrm{NO}_{3}^{-}$ & 4,93 & 5,07 & 0,036805 \\
\hline $\begin{array}{l}\text { BRS x BRN x } \mathrm{NO}_{3}^{-} \\
\text {Incubação: } 28 \text { dias (Y3) }\end{array}$ & $-5,51$ & $-5,66$ & 0,029871 \\
\hline Constante & 40,01 & 31,63 & 0,000998 \\
\hline Curvatura & 13,80 & 4,23 & 0,051602 \\
\hline Concentração inicial de BRS & 4,86 & 3,84 & 0,061491 \\
\hline Concentração inicial de BRN & 2,57 & 2,03 & 0,178919 \\
\hline Concentração inicial de nitrato & $-1,38$ & $-1,09$ & 0,389623 \\
\hline BRS x BRN & $-5,09$ & $-4,03$ & 0,056464 \\
\hline $\mathrm{BRS}_{x} \mathrm{NO}_{3}^{-}$ & 3,66 & 2,89 & 0,101787 \\
\hline $\mathrm{BRN} \times \mathrm{NO}_{3}^{-}$ & 4,91 & 3,88 & 0,060525 \\
\hline $\mathrm{BRS} \times \mathrm{BRN} \times \mathrm{NO}_{3}^{-}$ & $-8,13$ & $-6,42$ & 0,023379 \\
\hline
\end{tabular}

$(29,87)$ maior que o crítico $(19,0)$. Sendo assim, pode-se aferir que para o tempo de incubação de 28 dias, o modelo não se ajustou bem aos dados. Provavelmente, as condições ideais para a redução da produção de sulfeto foram atingidas em tempo menor do que 28 dias.

Diante dos resultados apresentados, foi realizada apenas a análise estatística da geração de sulfeto com 7 e 14 dias de incubação, uma vez que para estas condições os modelos são tidos como ajustados (Tabela 1). Para a produção de sulfeto no período de 7 dias (Y1), observou-se que os menores valores de sulfeto produzido ocorreram nos experimentos $1,5,7,9,10$ e 11 , sendo que nos experimentos 9, 10 e 11, que correspondem aos pontos centrais do planejamento experimental, foram verificadas as menores concentrações. Assim, pode-se concluir que as menores quantidades de sulfeto produzidas estão diretamente relacionadas com concentrações de BRS iguais ou inferiores a $10^{4} \mathrm{NMP} \mathrm{mL}^{-1}$. Nestas condições, o aumento da concentração inicial de $\mathrm{NO}_{3}{ }^{-}$(do nível inferior para o superior) manteve a concentração de sulfeto baixa (experimentos 1 e 5) e reduziu sua produção (experimentos 3 e 7). Os experimentos 2, 4 e 8 apresentaram os maiores valores de sulfeto produzido, nos quais maiores concentrações iniciais de BRS foram empregadas. Dentre todas as 
Tabela 3. Análise da variância para as respostas Y1, Y2 e Y3

\begin{tabular}{|c|c|c|c|c|}
\hline Causa de Variação & $\begin{array}{c}\text { Soma } \\
\text { Quadrática }\end{array}$ & $\begin{array}{l}\text { Graus de } \\
\text { Liberdade }\end{array}$ & $\begin{array}{c}\text { Média } \\
\text { Quadrática }\end{array}$ & $\mathrm{F}_{\text {cal }}$ \\
\hline \multicolumn{5}{|c|}{ Incubação: 7 dias (Y1) } \\
\hline Regressão & 2059,15 & 5 & 411,83 & 184,78 \\
\hline Resíduos & 8,915 & 4 & 2,23 & \\
\hline Falta de ajuste & 8,125 & 2 & 4,06 & 10,28 \\
\hline Erro puro & 0,790 & 2 & 0,39 & \\
\hline Total & 2068,065 & 9 & & \\
\hline \multicolumn{5}{|l|}{$\mathrm{R}^{2}=0,9957$} \\
\hline \multicolumn{5}{|c|}{ Incubação: 14 dias (Y2) } \\
\hline Regressão & 827,40 & 5 & 165,48 & 11,72 \\
\hline Resíduos & 56,49 & 4 & 14,12 & \\
\hline Falta de ajuste & 41,32 & 2 & 20,66 & 2,72 \\
\hline Erro puro & 15,17 & 2 & 7,58 & \\
\hline Total & 883,89 & 9 & & \\
\hline \multicolumn{5}{|l|}{$\mathrm{R}^{2}=0,9360$} \\
\hline \multicolumn{5}{|c|}{ Incubação: 28 dias (Y3) } \\
\hline Regressão & 532,32 & 5 & 106,46 & 0,54 \\
\hline Resíduos & 790,35 & 4 & 197,59 & \\
\hline Falta de ajuste & 764,74 & 2 & 382,37 & 29,87 \\
\hline Erro puro & 25,61 & 2 & 12,80 & \\
\hline Total & 1322,67 & 9 & & \\
\hline $\mathrm{R}^{2}=0,4025$ & & & & \\
\hline
\end{tabular}

condições avaliadas, a mais efetiva para a diminuição da acidificação, com geração de apenas $0,4-1,6 \mathrm{mg} \mathrm{S}^{2-} \mathrm{L}^{-1}$ (para uma população inicial de BRS e BRN de $10^{4} \mathrm{NMP}^{-1}$ ), consistiu na aplicação de 427,5 $\mathrm{mg} \mathrm{L}^{-1}$ de nitrato no sistema.

Os fatores considerados significativos para a produção de sulfeto, no intervalo de 7 dias, podem ser facilmente visualizados pelo emprego do diagrama de Pareto, Figura 1. Os efeitos nos quais os retângulos se dispõem após a linha divisória $(p=0,05)$ podem ser considerados significativos no modelo matemático.

Analisando-se os fatores, observa-se que as populações de BRS e BRN apresentaram efeitos positivos na produção de sulfeto, ou seja, o aumento dessas populações contribuía para o aumento da produção de sulfeto, sendo o efeito da população de BRS consideravelmente maior que o da população de BRN. Nota-se também que as interações BRS, BRN e $\mathrm{NO}_{3}^{-}$e BRS e BRN influenciaram significativamente a produção de sulfeto. A concentração de $\mathrm{NO}_{3}{ }^{-}$foi o único efeito que influenciou significativamente na redução da produção de sulfeto (sinal negativo), o que implica dizer que o aumento da concentração de nitrato conduzia à redução da produção de sulfeto. $\mathrm{O}$ comportamento do modelo para a produção de sulfeto também pode ser visualizado através de gráficos das médias, mediante variação das populações de BRS e BRN e concentrações de nitrato, Figura 2.

Menores valores de sulfeto foram obtidos com baixa concentração inicial de BRS, ou seja, aumentando-se a concentração de BRS, a produção de sulfeto aumentava. No entanto, a concentração final de sulfeto foi menor na presença de maiores concentrações de $\mathrm{NO}_{3}^{-}$. Na presença de baixas concentrações de BRS e BRN, a injeção de nitrato não teve qualquer efeito sobre a produção de sulfeto. Quando a população de $\mathrm{BRN}$ foi maior que a de $\mathrm{BRS}\left(10^{6}\right.$ vezes maior) a aplicação de maiores concentrações de $\mathrm{NO}_{3}$ - reduziu consideravelmente a produção de sulfeto (em torno de $74 \%$ - Tabela 1). Redução menor

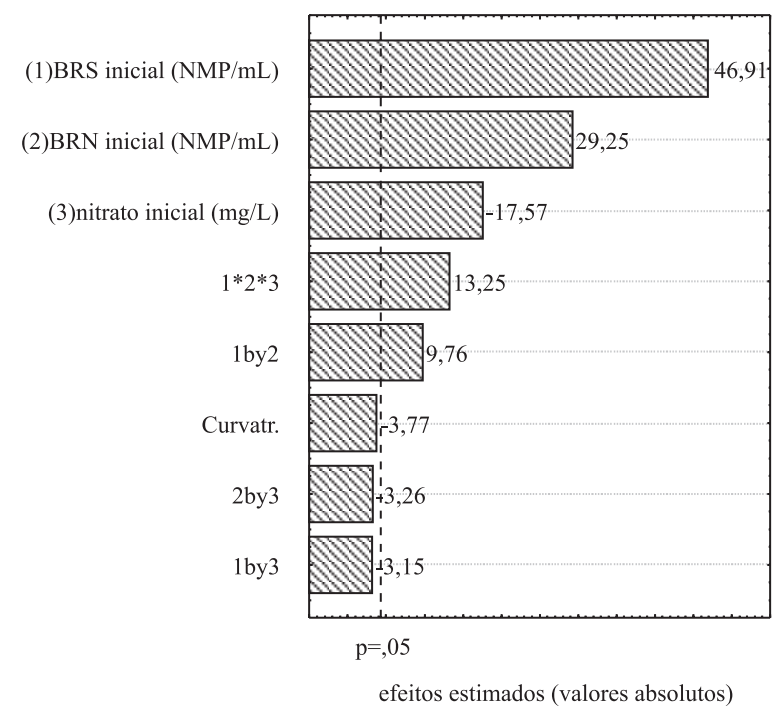

Figura 1. Diagrama de Pareto para a resposta Y1 - 7 dias de incubação

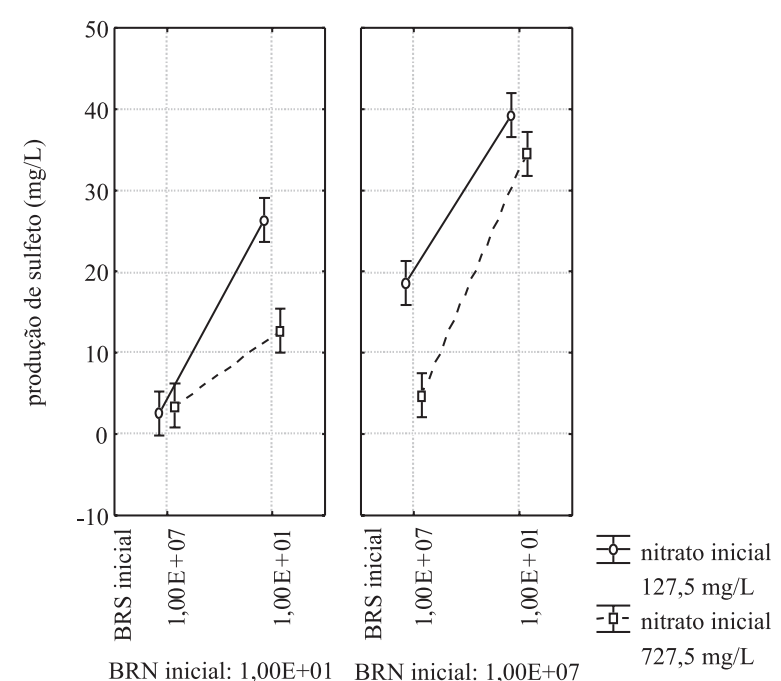

Figura 2. Gráfico das médias para a resposta Y1 - 7 dias de incubação

(em torno de 52\% - Tabela 1) foi observada para baixas concentrações de BRN e altas concentrações de BRS ao se aumentar a concentração de nitrato, o que pode indicar a utilização de $\mathrm{NO}_{3}{ }_{3}^{-}$pelas BRS. Quando ambas as populações estavam presentes em níveis mais elevados $\left(10^{7}\right.$ NMP mL $\left.{ }^{-1}\right)$, a injeção de elevada dosagem de $\mathrm{NO}_{3}^{-}\left(727,5 \mathrm{mg} \mathrm{L}^{-1}\right)$ não evitou a produção de sulfeto. Os dados sugerem que a injeção de maiores quantidades de $\mathrm{NO}_{3}^{-}$pode não resolver o problema de souring em alguns reservatórios. Dados da literatura mostram que a concentração de nitrato a ser adotada para a mitigação do souring é dependente de fatores como a concentração da fonte de carbono a ser oxidada e relaciona-se intensamente com as características microbiológicas e ambientais do reservatório. Jenneman et al. ${ }^{7}$ demonstraram,

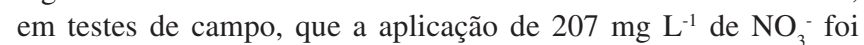
suficiente para a remoção total de sulfeto; enquanto a inibição de

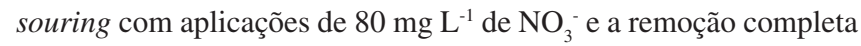
de $\mathrm{H}_{2} \mathrm{~S}$ com dosagens de $100 \mathrm{mg} \mathrm{L}^{-1}$ de $\mathrm{NO}_{3}^{-}$é reportada por outros autores. ${ }^{9}$ Londry e Sulfita, ${ }^{25} \mathrm{em}$ testes de laboratório, propuseram dosagens bem mais elevadas, da ordem de $3100 \mathrm{mg} \mathrm{L}^{-1} \mathrm{de} \mathrm{NO}_{3}^{-}$para reduzir em $90 \%$ a redução de sulfato. Em contrapartida, Myhr et al..$^{26}$

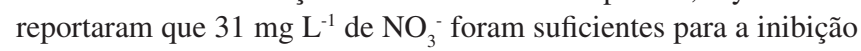
completa da produção de sulfeto em testes em coluna que simulavam o comportamento de reservatórios de petróleo. 
Para a resposta correspondente a 14 dias de incubação (Y2), os resultados demonstram que, com exceção do experimento 5, a produção de sulfeto alcançou níveis superiores a $23 \mathrm{mg} \mathrm{L}^{-1}$. Tais valores podem estar relacionados com o esgotamento da fonte de nitrato no sistema. O menor valor de sulfeto foi detectado no experimento 5, que apresentava como condições iniciais baixas concentrações de BRS e BRN. Este foi o único ensaio em que o nitrato ainda se mantinha disponível no sistema ao final dos 14 dias de incubação, verificando-se valores próximos a $60 \%$ da concentração inicial do íon (436,2 $\left.\mathrm{mg} \mathrm{L}^{-1}\right)$. Mantendo-se baixas concentrações iniciais de BRS e BRN e menor injeção de nitrato (experimento 1), já não foi possível impedir a produção de sulfeto, que atingiu valor superior a $40 \mathrm{mg} \mathrm{L}^{-1}$. Assim, pode-se considerar que, em todos os experimentos, após o esgotamento do nitrato ocorreu elevada produção de sulfeto (23,9-42,2 $\mathrm{mg} \mathrm{L}^{-1}$, Tabela 1), alcançando-se valores semelhantes independente da concentração inicial de nitrato no sistema. O gráfico de Pareto (Figura 3) apresenta os fatores mais significativos na produção de sulfeto para o tempo de 14 dias de incubação. Nota-se que tanto os termos de interação como os efeitos principais são importantes na resposta. No entanto, percebe-se que o efeito da população de BRS não é mais significativo na produção de sulfeto. $O$ termo de interação BRS.BRN.NO ${ }_{3}^{-}$(efeito negativo) foi o mais importante, seguido do efeito BRN, da interação BRN.NO ${ }_{3}^{-}$(com efeitos positivos) e do efeito $\mathrm{NO}_{3}^{-}$, que ainda se mantém como efeito negativo, ou seja, o aumento de sua concentração provocava redução na resposta. Isso nos leva a concluir que o nitrato, mesmo na presença de baixa população de BRN, pode mitigar a produção de sulfeto na presença de espécies de BRS capazes de utilizar este íon como receptor final de elétrons. ${ }^{9}$

Pelo comportamento dos gráficos das médias (Figura 4) observa-se que para as menores concentrações iniciais de BRS e BRN, a injeção de maior concentração de nitrato $\left(727,5 \mathrm{mg} \mathrm{L}^{-1}\right)$ conseguiu manter a produção de sulfeto baixa. Quando se aumentou, em cerca de $10^{6}$, a população inicial de BRS uma maior injeção de nitrato não apresentou efeito na mitigação do sulfeto. Quando se aumentou em $10^{6}$ a população de BRN, independente da concentração inicial de BRS, maiores injeções de nitrato não garantiram a queda da produção de sulfeto. Uma explicação para tal resultado seria o consumo acentuado de nitrato por ambas populações de BRN e BRS logo no início do experimento, reduzindo a disponibilidade de nitrato e aumentando a população de BRS que passaria a reduzir o sulfato. Vários autores citam que espécies dos gêneros Desulfovibrio, Desulfobulbus e Desulfomonas são capazes de utilizar nitrato como receptor final de elétrons, formando amônia como produto final através

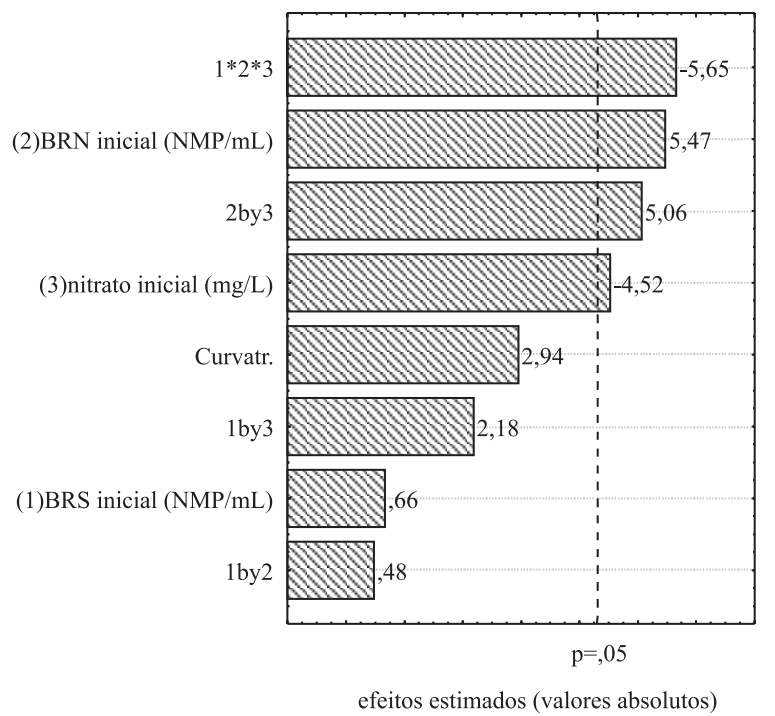

Figura 3. Diagrama de Pareto para a resposta Y2 - 14 dias de incubação de uma via desassimilativa que envolve a enzima nitrato redutase. ${ }^{27,28}$ Esta proposição pode ser confirmada pelo balanço termodinâmico das reações de redução de nitrato e sulfato por BRS, que apresentam valores de $\Delta \mathrm{G}^{\circ}$ de $-149,2$ e $-172,0 \mathrm{~kJ}$ por mol de $\mathrm{H}_{2}$, respectivamente. A capacidade de redução de nitrato por BRS parece se associar à disponibilidade de íons sulfato no meio, ou seja, o metabolismo seria direcionado à redução de nitrato quando sulfato estivesse limitado. ${ }^{27}$ No entanto, outros autores descrevem a habilidade de determinadas linhagens de Desulfovibrio em reduzir nitrato na presença de íons sulfato em concentrações não limitantes. ${ }^{15}$ Esta afirmativa procede, tendo em vista a similaridade entre os ganhos energéticos das reações de redução de nitrato e sulfato pelas BRS. A inibição da redução de sulfato pela redução de nitrato em BRS ocorre quando as concentrações de nitrato são proporcionais às concentrações disponíveis de fonte de carbono. Assim, nessas condições, o metabolismo das BRS (se contêm genes para a redução de nitrato) seria completamente direcionado para a redução do nitrato. ${ }^{9}$ Cabe ressaltar que, em qualquer dos casos mencionados, as BRS permanecerão metabolicamente ativas, apenas deixando de produzir sulfeto. Logo, a biogênese de sulfeto voltará a ocorrer em uma eventual disponibilidade de sulfato. Neste caso, tem-se a agravante da acidificação do reservatório permanecer intensa, tendo em vista que a população de BRS se encontra em maior número e já adaptada às condições ambientais do reservatório.

Resumidamente, para a maioria das condições avaliadas, uma maior injeção de nitrato, no intervalo de 14 dias, não impediu uma alta produção de sulfeto. A interseção ou o cruzamento das linhas nos gráficos das médias (Figura 4) indica a importância dos termos de interação nos mecanismos da resposta investigada (Y2).

\section{CONCLUSÕES}

Os resultados demonstraram que a relação entre as concentrações de BRS e BRN tem grande influência na quantidade e no modo de aplicação de nitrato para mitigação do souring. A produção de sulfeto pode ser reduzida pela adição de nitrato quando baixas concentrações de BRS e BRN estão presentes, sendo o menor valor de sulfeto obtido nesta condição com uma maior concentração de nitrato e em intervalo menor que 14 dias. O nitrato, na presença de baixa concentração de BRN, pode mitigar a produção de sulfeto devido a espécies de BRS serem capazes de utilizar nitrato como receptor final de elétrons. No entanto, o aumento da população de BRN não implica necessariamente em redução da produção de sulfeto, mesmo quando maiores concentrações de nitrato são aplicadas. Sob esta condição, provavelmente ocorre um acentuado consumo de nitrato, reduzindo
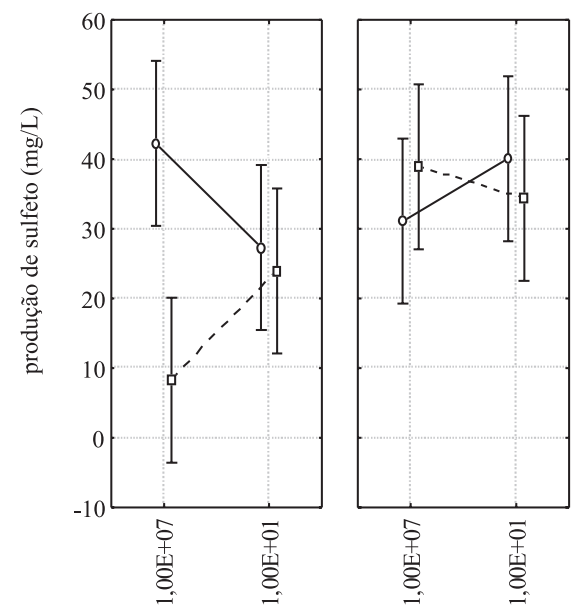

고으 nitrato inicia $127,5 \mathrm{mg} / \mathrm{L}$ - 모- nitrato inicial BRN inicial: $1,00 \mathrm{E}+01 \quad$ BRN inicial: $1,00 \mathrm{E}+07 \quad 727,5 \mathrm{mg} / \mathrm{L}$ 
sua disponibilidade no meio e permitindo que a população de BRS utilize novamente o sulfato com receptor final de elétrons. Os resultados também sugeriram que as aplicações de nitrato para controle do processo de souring devem seguir um regime contínuo. A condição mais efetiva para a redução da produção de sulfeto (concentrações finais de 0,4-1,6 $\mathrm{mg} \mathrm{L}^{-1}$ ) foi obtida com população inicial de BRS e BRN de $10^{4} \mathrm{NMP} \mathrm{mL}^{-1}$ e $427,5 \mathrm{mg} \mathrm{L}^{-1}$ de nitrato.

\section{MATERIAL SUPLEMENTAR}

Está disponível em http://quimicanova.sbq.org.br, na forma de arquivo .PDF, com acesso livre. Para confirmar que as condições ideais para a redução da produção de sulfeto foram atingidas em tempo menor do que 28 dias, são apresentados os gráficos da probabilidade normal dos resíduos (Figura 1S). Um resumo dos dados de sulfeto produzido ao longo do tempo de incubação $(7,14$ e 28 dias) para diferentes concentrações iniciais de BRS, BRN e nitrato é apresentado na forma de gráficos (Figura 2S).

\section{AGRADECIMENTOS}

Os autores agradecem à CAPES e ao CNPq, pela bolsa concedida e aportes financeiros concedidos ao grupo de pesquisa, e à Petróleo Brasileiro S.A. (Petrobras) pelo fornecimento do consórcio de BRS e água produzida.

\section{REFERÊNCIAS}

1. Davidova, I.; Hicks, M. S.; Fedorak, P. M.; Sulfita, J. M.; J. Ind. Microbiol. Biotechnol. 2001, 27, 80.

2. Vance, I.; Thrasher, D. R. Em Petroleum Microbiology; Ollivier, B.; Magot, M., ed.; American Society for Microbiology: Washington DC, 2005, cap. 7.

3. Tang, K.; Baskaran, V.; Nemati, M.; Biochem. Eng. J. 2009, 44, 73.

4. Chernicharo, C. A. L.; Princípios do Tratamento Biológico de Águas Residuárias - Reatores Anaeróbios, $2^{\mathrm{a}}$ ed., Ed. UFMG: Belo Horizonte, 2007.

5. Weijma, J.; Bots, E. A. A.; Tandlinger, G.; Stams, A. J. M.; Hulshoff Pol, L. W.; Lettinga, G.; Water Res. 2002, 36, 1825.

6. Mohan, S. V.; Rao, N. C.; Prasad, K. K.; Sarma, P. N.; Process Biochem. 2005, 40, 2849.

7. Jenneman, G. E.; Moffitt, P. D.; Bala, G. A.; Webb, R. H.; Society of Petroleum Engineers Production \& Facilities 1999, 14, 219.

8. Nemati, M.; Jenneman, G. E.; Voordouw, G.; Biotechnol. Bioeng. 2001, 74,424 .
9. Dinning, A. J.; Oliphant, D.; Vik, E. A.; Bruas, L.; Proceedings of SPE International Symposium on Oilfield Chemistry, Houston, United States, 2005.

10. Kaster, K. M.; Grigoriyan, A.; Jenneman, G. E.; Voordouw, G.; Appl. Microbiol. Biotechnol. 2007, 75, 195.

11. Lysnes, K.; Bødtker, G.; Torsvik, T.; Bjørnestad, E. Ø.; Sunde, E.; Appl. Microbiol. Biotechnol. 2009, 83, 1143, doi: 10.1007/s00253-009-20157.

12. Kaur, G.; Mandal, A. K.; Nihlani, M. C.; Lal, B.; Int. Biodeter. Biodegr. 2009, 63, 151.

13. Lens, P.; Massone, A.; Rozzi, A.; Verstraete, W.; Water Res. 1995, 29 , 857.

14. Energy Institute; The stimulation of nitrate-reducing bacteria (NRB) in oilfield systems to control sulphate-reducing bacteria (SRB), microbiologically influenced corrosion (MIC) and reservoir: an introductory review, Energy Institute: London, 2003.

15. Dunsmore, B. C.; Whitfield, T. B.; Lawson, P. A.; Collins, M. D.; Proceedings of Corrosion 2004, New Orleans, United States, 2004.

16. Sunde, E.; Lillebø, B. P.; Bødtker, G.; Torsvik, T.; Thorstenson, T.; Proceedings of Corrosion 2004, New Orleans, United States, 2004.

17. Maxwell, S.; Spark, I.; Proceedings of SPE International Symposium on Oilfield Chemistry, Houston, United States, 2005.

18. Bødtker, G.; Lysnes, K.; Torsvik, T.; Bjørnestad, E. Ø.; Sunde, E.; J. Ind. Microbiol. Biotechnol. 2009, 36, 439.

19. Dunsmore, B.; Youldon, J.; Ian Vance, D. R. T.; Ind. Microbiol. Biotechnol. 2006, 33, 454.

20. Postgate, J. R.; The sulphate-reducing bacteri, University Press: Cambridge, 1984.

21. Vieira, D. S.; Sérvulo, E. F. C.; Cammarota, M. C.; Environ. Technol. 2005, 26, 915.

22. Jacobs, M. B.; Braverman, M. M.; Hocheiser, S.; Anal. Chem. 1957, 29, 1349.

23. Lutterbach, M. T. S.; França, F. P.; Braz. J. Chem. Eng. 1997, 14, 81.

24. American Public Health Association; Standard methods for the examination of water and wastewater, APHA, AWWA, WPCF: Washington DC, 1992.

25. Londry, K. L.; Sulfita, J. M.; J. Ind. Microbiol. Biotechnol. 1999, 22, 582.

26. Myhr, S.; Lillebø, B. L. P.; Sunde, E.; Beeder, J.; Torsvik, T.; Appl. Microbiol. Biotechnol. 2002, 58, 400.

27. Cypionka, H. Em Biotechnology Handbooks; Barton, L.; ed.; Plenum Press: New York, 1995, vol. 8, cap. 6.

28. Moura, I.; Bursakov, S.; Costa, C.; Moura, J. J. G.; Anaerobe 1997, 3 , 279. 


\section{EFEITO DA APLICAÇÃO DE NITRATO NA REDUÇÃO BIOGÊNICA DE SULFETO SOB DIFERENTES CONCENTRAÇÕES INICIAIS DE BACTÉRIAS REDUTORAS DE NITRATO E SULFATO}

\section{Kally Alves de Sousa, Magali Christe Cammarota* e Eliana Flávia Camporese Sérvulo}

Departamento de Engenharia Bioquímica, Escola de Química, Universidade Federal do Rio de Janeiro, Av. Horácio Macedo 2030, Centro de Tecnologia, Bl. E, Ilha do Fundão, 21949-900 Rio de Janeiro - RJ, Brasil

Para confirmar que as condições ideais para a redução da produção de sulfeto foram atingidas em tempo menor do que 28 dias, analisou-se os gráficos da probabilidade normal dos resíduos (Figura 1S). Percebe-se que, para os tempos de incubação de 7 e 14 dias (Figuras 1SA e 1SB, respectivamente), os resíduos obedecem à distribuição normal, fato não observado para o tempo de 28 dias de incubação (Figura 1SC).

$\mathrm{Na}$ Figura $2 \mathrm{~S}$ é apresentado um resumo dos dados de sulfeto produzido ao longo do tempo de incubação para diferentes concentrações iniciais de BRS, BRN e nitrato. Uma análise dos dados revela que somente mediante baixas concentrações iniciais de BRS e BRN (101 NMP mL-1) consegue-se manter a produção de sulfeto em baixos níveis $(<10 \mathrm{mg} \mathrm{L}-1)$ por até 28 dias através de uma dosagem única e elevada de nitrato (Experimentos 1 e 5). Quando uma das populações (BRS ou BRN) apresenta concentrações iniciais elevadas (107 NMP mL-1), o consumo de nitrato parece ser acentuado, e uma dosagem única de nitrato, mesmo em valores mais elevados, não evita a produção de sulfeto aos 14 e 28 dias (Experimentos 2 e 6; 3 e 7). Quando as duas populações de BRS e BRN são elevadas, já aos 7 dias ocorrem altas produções de sulfeto com baixas e altas concentrações de nitrato (Experimentos 4 e 8). Os resultados obtidos sugerem a necessidade de aplicações contínuas de nitrato no sistema para o controle do processo de acidificação, uma vez que o nitrato inicial, mesmo em altas concentrações, pode se esgotar, tanto pelo consumo pelas BRN como pelas BRS.
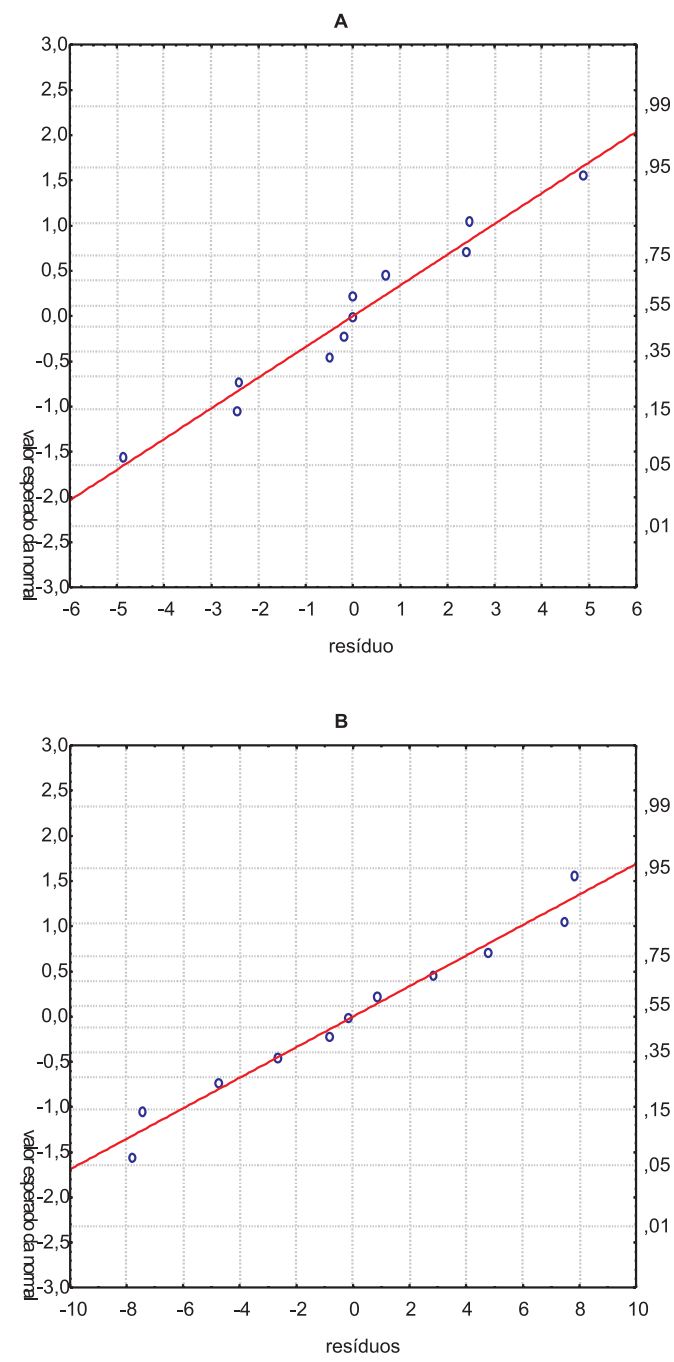

C

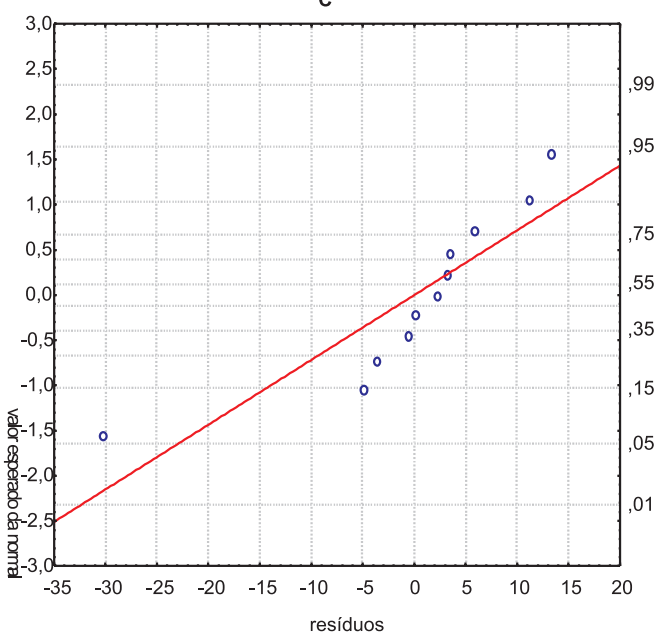

Figura 1S. Gráficos da probabilidade normal dos resíduos 


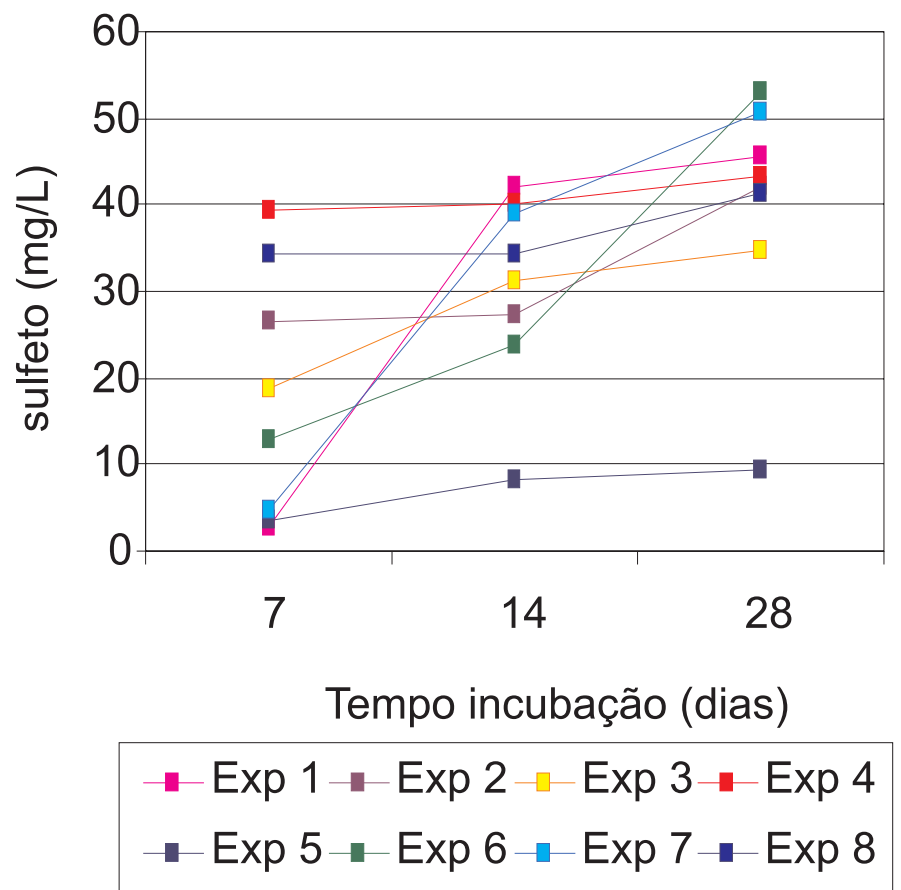

Figura 2S. Gráficos da produção de sulfeto ao longo do tempo de incubação (7, 14 e 28 dias) para diferentes concentrações iniciais de BRS, BRN e nitrato 